\title{
Bubonic plague: doubts and diagnoses
}

The identification of bubonic plague in the distant past is fraught with many difficulties, most of which arise from the complex ecological relationship of the rodent and flea vectors, climate (particularly temperature and relative humidity), the physical environment and the existence of the bubonic, pneumonic and septicaemic forms. A further complication is that the term "plague" was formerly used as a generic term for any epidemic disease causing high mortality. ${ }^{1}$ In the case of plague, more than any other disease, certain identification is only possible for outbreaks since 1894 when Yersin ${ }^{2}$ and Kitasato ${ }^{3}$ isolated and identified the plague bacillus.

From 1896 onwards plague spread from China to every part of the world and millions died. Research was intense and within the next two decades the disease and its ecology had been defined so that the identification of plague could be made with confidence. Yet it was clear from the outset that there were difficulties with clinical diagnosis. In the Bombay plague of 1896-97 it was recognised that in its early stages plague might be mistaken for ague, remittent fever, syphilis, pneumonia, epilepsy, cerebral apoplexy, uraemic coma, ulcer with inflammation of lymph glands, diarrhoea, debility, marasmus and phthisis. ${ }^{4}$ Whilst lymph gland enlargement was accepted as a reasonably reliable feature, isolation of the organism or post-mortem examination was required to confirm the diagnosis.

Since then, sophisticated and specific serological techniques have been developed, and 100 years after the original isolation one would expect that the disease could be identified easily, especially in countries with a long history of plague which still maintained a permanent surveillance system. However, this is not the case. In the autumn of 1994, plague was reported in India, and by Oct. 5 a total of 5559 suspected cases of plague were reported in various parts of the country; of these 58 had died. Media-induced panic caused many to flee the affected areas, just as occurred in Bombay in 1896-97-when no less than 377866 people left the city-and in London in 1665 and other plague years. What was less expected in 1994 was that there are serious doubts about the diagnosis of plague in many cases, ${ }^{5}$ which has led to the suggestion that the "epidemic" in Surat was caused by more than one disease. ${ }^{6}$

This current confusion emphasises the difficulty of interpreting the figures on plague mortality earlier this century, especially in India where, between 1896 and
1917, almost 10 million people are said to have died of plague. If this was an overestimate, it still represented only $0.135 \%$ of the total population per annum, severe enough but paling into insignificance beside the 1665 plague of London that killed between 15 and $20 \%$ of the population during the late summer months alone, or the fourteenth century Black Death that is variously estimated to have removed between 30 and $50 \%$ of the population of Britain in the years 1348-50. ${ }^{7}$ Despite the severe epidemics of plague early in the twentieth century, the received wisdom is that the Black Death was the greatest episode of bubonic plague in history and a voluminous literature has grown up around it. Yet for this outbreak, as for all others between 1348 and 1666 in the British Isles, the indices deemed essential for a diagnosis of plague are almost totally absent. There is no information on case mortality, the rodent epizootic or even the rodent concerned and its fleas. The very few clinical observations that were made are ambiguous but, although localised, were deemed adequate to account for widespread mortality. Despite this, there are rarely doubts in the minds of most authors concerned with either the Black Death or later epidemics and a confident retrospective diagnosis of bubonic or pneumonic plague is presented.

Notwithstanding the recent difficulty in India, the baseline data laid down by such bodies as the Plague Research Commission can still form a valid basis for comparison with past outbreaks, especially with regard to climatic factors, diffusion, rats, fleas and the epizootic. Whilst these may not be sufficient to provide a definite diagnosis of plague, they can serve to eliminate outbreaks that differ to such a degree that they are outside the tolerance limits for plague variation. Of all the so-called plague epidemics in northern Europe, the Black Death is the one to lie furthest outside such limits.?

Plague spreads or, more accurately, diffuses, very slowly pursuing what has been called a "faltering progress", yet the Black Death spread very much faster and in all habitats, including even mountainous areas. In Genoa, plague deaths were recorded in every part of the city within a couple of days of the docking of ships carrying plague; for plague to spread enough infected rats and fleas would have had to come ashore, infect the local rat population, initiate the epizootic and then infect the first human-a fairly long and protracted process.

A continuous minimum temperature of $21^{\circ} \mathrm{C}$ is 
essential for flea breeding yet spread of the Black Death continued in winter during one of the coldest periods of the last one thousand years. The argument that pneumonic plague accounted for the rapid diffusion and winter spread is less than persuasive since outbreaks of pneumonic plague tend to be selflimiting, losing virulence with successive person to person transfer; furthermore epidemics of pneumonic plague still require the epizootic to introduce the organism into the community. Of the population of fourteenth century England, $90 \%$ lived in villages and hamlets and there was wide variation in population density, from 19 per square mile in Cheshire to 109 per square mile in Norfolk. Despite this and other factors that would have limited diffusion, the Black Death spread rapidly.

The Black rat, Rattus rattus, and the rat flea, Xenopsylla cheopis, have proved the most effective combination for plague propagation. Both species are warm-adapted with the rat confined almost entirely to human habitations in a cool temperate climate. This alone would have resulted in the localisation of plague and retarding of diffusion. In fourteenth century Britain, the Black rat was present but little is known of its distribution and nothing about its abundance. There is no information about the flea during this period. The rat epizootic was known in Eastern folklore as the precursor of plague and when rats began to die people would leave their houses and live in the open until it was judged safe to return. During modern outbreaks the epizootic has been a constant and obvious feature yet there is no mention anywhere in north-west Europe of an epizootic at any time during the Black Death or other epidemics of "plague" up to and including 1666 . This must be one of the most compelling points against the disease being plague, and it seems extraordinary that the chroniclers of the Black Death, who recorded the deaths of sparrows, cattle, sheep and even bees, would have failed to notice the deaths of rats inside their houses in advance of the human epidemic.

Accounts of swellings, skin discolouration, carbuncles and pulmonary involvement have at times all been selected as indisputable evidence of plague. These were undoubtedly present but given the spectrum of ailments in the population they could have been the result of other organisms and are all found in conditions other than plague. It is significant that some oft-recurring symptoms in the literature have been ignored, presumably because they are not typical of plague. Amongst the most prominent of these is the evacuation of blood, often black, from the body orifices. A multi-origin high mortality could include bubonic plague as part of the cause, particularly in favourable high density urban habitats in the summer months, and this would remove the awkward necessity of devising impossible biological scenarios in order to equate "plague" with bubonic plague and make what has become a historical necessity out of a biological improbability.
At last, though, there are signs that the Black Death is being recognised as a unique medical event, but despite this acceptance of its singular qualities there is still a reluctance to abandon plague as its cause, but this creates further difficulties. In 1983, despite the fact that the epidemic referred to in Avignon in 1348 began in mid-winter, one reviewer regarded the presence of axillary swellings and lung haemorrhage as evidence of plague throughout the area covered by the Black Death, ${ }^{8}$ but by 1994 , the same author recognised the unique nature of the Black Death and suggested that it was a freak instance of bubonic plague in which a very rare coincidence of circumstances turned it into a bigger killer than it has every been since. ${ }^{9}$ However, plague is a stable organism operating within narrow margins due to the constraints imposed by both vectors and climate, ensuring that the conditions that determine the spread of plague in epidemic form are very rigid. The various links in the infective chain, from rat to flea and then to man are delicately adjusted and one weakness is enough to spoil the efficiency of the whole sequence or even to break it altogether.

In Tudor and Stuart London during the years of high mortality between 1540 and 1665 , there was sufficient variation in the mortality patterns to accommodate plague alongside other significant causes of death. At least three patterns of death are evident; one resembles plague or some other single disease causing a steady incremental increase of deaths; a second has the steep rise in deaths characteristic of enteric disease to be expected during the summer in a city with rudimentary hygiene and a contaminated water supply; the third consists of a generally higher weekly mortality that might continue for most of the year without any peak of deaths. ${ }^{10}$ These and other variations have been masked by the tendency to aggregate all burials for the great plague years, thus producing a pyramidal pattern that gives an impression of epidemic unity across the city. ${ }^{11}$

Interestingly, neighbouring parishes had entirely different patterns of mortality and timing of their epidemics; parishes were not biological entities, suggesting that these differences could be the product of ecological factors such as housing type, population density, food stores, markets and water supply. A study of these and their relationship to mortality variation would be valuable.

A range of diseases operating concurrently in the late summer would result in a wide variety of symptoms and it is clear from the lists of plague "diagnosticks" that such was probably the case. Some of these were of a general nature common to other ailments, e.g., "Heat and thirstiness", but, in his account of the 1665 plague of London, William Boghurst included buboes and carbuncles at eighth place in his diagnosticks. In fifth place was "Bleeding at the nose and sometymes mouth, Hemroids and menses". In all, 21 symptoms were listed, some of them repeated in a further 46 "evil signes or presagers of the plague". ${ }^{12}$ 
It is difficult, if not impossible, to identify bubonic plague of former times with certainty; even the present has its problems. What is important is not to attempt to fit bubonic plague into high mortality situations that are clearly outside the limits that are acceptable for plague. If that is done, plague can occupy a

\section{References}

1. Pye G. A discourse of the plague; wherein Dr Mead's notions are consider'd and refuted. London: J. Darby. 1721: 3-4.

2. Yersin M. La peste bubonique à Hong-kong. Annales de l'Institut Pasteur 1894; 8: 662-667.

3. Kitasato $\mathrm{S}$. The bacillus of bubonic plague. Lancet 1894; 2: $428-430$.

4. Gatacre WF. Report on the bubonic plague in Bombay. Bombay: Times of India 1897: 52.

5. Dar L, Thakur R, Dar VS. India : is it plague? Lancet 1994; 344 : 1359.

6. John TJ. India: is it plague? Lancet $1994 ; 344: 1359-1360$.

7. Twigg G. The Black Death: a biological reappraisal. London, Batsford. 1984. position in the epidemic scene that is more in keeping with its complex biology and known capabilities.

G. TwIGG

Department of Biology, Royal Holloway and Bedford College, Egham, Surrey, TW20 0EX

8. Hatcher J. BBC “Timewatch”. 1983.

9. Hatcher J. In: Weightman G, "Maybe the black rat didn't do it". The Independent on Sunday, 9 October, 1994.

10. Twigg G. Plague in London: spatial and temporal aspects of mortality. In: Champion JAI (ed) Epidemic disease in London. Centre for Metropolitan History, working papers series, no. 1. University of London, Institute of Historical Research. 1993: 1-17.

11. Shrewsbury JFD. A history of bubonic plague in the British Isles. Cambridge University Press. 1970; 50, 463.

12. Boghurst W. Loimographia: an account of the great plague of London in the year 1665. London, Shaw and Sons. 1894: 21-23. (Printed for the Epidemiological Society of London from the British Museum Sloane MS.349). 